\title{
Review
}

\section{The revised IUCN protected area management categories: the debate and ways forward}

\author{
Nigel Dudley, JefFrey D. Parrish, Kent H. Redford and Sue Stolton
}

\begin{abstract}
The global protected area estate is the world's largest ever planned land use. Protected areas are not monolithic and vary in their purpose, designation, management and outcomes. The IUCN protected area category system is a typology based on management objectives. It documents protected area types and is increasingly used in laws, policy and planning. As its role grows, the category system must be reactive to opinions and open to modifications. In response to requests from members IUCN undertook a 4-year consultation and recently published revised guidelines for the categories. These made subtle but important changes to the protected area definition, giving greater emphasis to nature conservation, protection over the long term and management effectiveness. It refined some categories and gave principles for application. Debates during revision were intense and highlighted many of the issues and challenges surrounding protected areas in the early 21 st century. There was a consensus on many issues including the suitability of different governance models (such as indigenous and community conserved areas), sacred natural sites, moving the emphasis of Category IV from habitat manipulation towards species and habitat protection, and recognition of legally defined zones within a protected area as different categories. However, there was considerable disagreement about the definition of a protected area, the appropriateness of some categories with extensive human use, the possibility of linking category classification with biodiversity outcomes, and recognition of territories of indigenous peoples. We map these debates and propose actions to resolve these issues: a necessary step if the world's protected area network is to be representative, secure and well managed.
\end{abstract}

Keywords IUCN, management categories, protected areas

Nigel Dudley* (Corresponding author) and Sue Stolton Equilibrium Research, 47 The Quays, Cumberland Road, Spike Island, Bristol, BS1 6UQ, UK. E-mail nigel@equilibriumresearch.com

JefFrey D. PARrish Freedom to Roam, Denver, USA

Kent H. Redford Wildlife Conservation Society, Bronx, New York, USA

${ }^{*}$ Also at: University of Queensland (Industry Fellow), Brisbane St Lucia, Queensland, Australia

Received 26 June 2009. Revision requested 7 September 2009.

Accepted 26 March 2010.

\section{Introduction}

The global protected areas estate is the world's largest 1 planned land use (Chape et al., 2005), now covering an estimated $11.3 \%$ of national terrestrial and marine territories (UNEP-WCMC, 2008), the majority having been designated in the last 50 years. However, this protected area estate is not monolithic, with great variation between protected areas in size, age, purpose, designation, governance, management and outcomes. Individual protected areas range from strict nature reserves, where human visitation is banned or strictly limited, to protected landscapes where long-established and permanent human communities follow management practices that can deliver nature conservation objectives. Protected areas can vary in size from sites of $<_{1}$ ha to reserves of millions of hectares, and from places run by governments to others run by private individuals or local communities. The spectrum within the global network of protected areas is characterized in IUCN's protected area category system, a typology that seeks to represent and systematize this variation based on a category of management objectives. A new set of guidelines to the categories has recently been published (Dudley, 2008), including subtle but important changes both to the definition of a protected area and to the categories themselves. The debates that accompanied the revision process encapsulate some of the key issues and challenges surrounding protected area policy and practice in the early $21 s t$ century. Here we summarize these debates and offer some policy recommendations for the international conservation community.

\section{Background}

Although the modern history of protected areas dates back to 1866 , when the British Colony of New South Wales in Australia initiated the creation of the Blue Mountains National Park, there was no systematic effort to clarify the terminology of protected areas until the 1933 International Conference for the Protection of Flora and Fauna in London. This recommended a four-stage typology: national park, strict nature reserve, fauna and flora reserve, and reserve with prohibition for hunting and collecting. The question of an international agreed nomenclature was raised again in 1961 when IUCN's new International Commission for National Parks (now known as the World Commission on Protected Areas, WCPA) edited the first World List of 
National Parks and Equivalent Reserves (ECOSOC, 1961). In 1975 IUCN began to develop a categories system based on management objectives (Phillips, 2002) and this was eventually published as a set of six categories (IUCN, 1994). IUCN's advice at that time was that governments should design appropriate protected area systems for their own particular conditions and apply the categories retrospectively (IUCN, 1994). Although designed primarily as a framework for reporting data to the World Database on Protected Areas (WDPA), the categories have increasingly also been used as an instrument for policy, planning and even legislation (Dillon, 2004). This extension beyond their original remit has led to both confusion and tension (Ravenel \& Redford, 2005). Categories that might have been assigned casually as a recording device sometimes later assumed far more significance with respect to allocation of government funds or to application of laws controlling management or human habitation. Two particular issues focused international attention on the growing significance of the IUCN categories. Firstly, there has been mounting concern that protected area designations were being used as an excuse for relocating indigenous peoples from their traditional territories (Colchester, 2003). Secondly, in 2000, IUCN members voted in favour of a recommendation at the World Conservation Congress suggesting that governments ban mining, mineral extraction and exploration in certain IUCN protected area categories, causing a furore in the mineral industry (Koziell \& Omosa, 2003).

In response to requests from members alarmed by these controversies and a resolution at the 2004 World Conservation Congress, IUCN undertook a 4-year consultation to identify points of contention and possible changes needed in the categories system. The process began with a project at the University of Cardiff, UK (Bishop et al., 2004), which also provided platforms for discussion at regional and global meetings, including the 2003 5th World Parks Congress, where a resolution was passed asking IUCN to update the categories. A task force of the IUCN WCPA was established to rewrite the guidelines, involving further consultation and a major international policy meeting in May 2007 in Spain (Dudley \& Stolton, 2008).

The new guidelines, issued in 2008 (Dudley, 2008), contain subtle but important changes to the definitions of both protected areas and the categories themselves. The 1994 definition was 'An area of land and/or sea especially dedicated to the protection and maintenance of biological diversity, and of natural and associated cultural resources, and managed through legal or other effective means' (IUCN, 1994), whereas the new definition is 'A clearly defined geographical space, recognised, dedicated and managed, through legal or other effective means, to achieve the longterm conservation of nature with associated ecosystem services and cultural values' (Dudley, 2008). The significance of these changes is discussed below.
In addition to changes in the definition of a protected area, significant amendments were made to the system of protected area categories. The number and broad distinctions between the categories of protected areas remain the same as in the 1994 iteration of the guidelines but there have been some changes in emphasis and the different categories are now described and differentiated in greater detail:

Category Ia (strict nature reserve) Set aside to protect biodiversity and also possibly geological/geomorphological features, where human visitation, use and impacts are strictly controlled and limited to ensure protection of the conservation values.

Category $\mathrm{Ib}$ (wilderness area) Usually large unmodified or slightly modified areas, retaining their natural character and influence, without permanent or significant human habitation, protected and managed to preserve their natural condition.

Category II (national park) Protect large-scale ecological processes, along with the complement of species and ecosystems characteristic of the area, which also provide a foundation for environmentally and culturally compatible spiritual, scientific, educational, recreational and visitor opportunities.

Category III (natural monument or feature) Protect a specific natural monument, which can be a landform, sea mount, submarine cavern, geological feature such as a cave or even a living feature, such as an ancient grove.

Category IV (habitat/species management area) Protect particular species or habitats, where management reflects this priority. Many will need regular active interventions to address the requirements of particular species or to maintain habitats, but this is not a requirement of the category.

Category $V$ (protected landscape) Where the interaction of people and nature over time has produced an area of distinct character with significant ecological, biological, cultural and scenic value and where safeguarding the integrity of this interaction is vital to protecting and sustaining the area and its associated values.

Category VI (protected areas with sustainable use of natural resources) Conserve ecosystems and habitats, together with associated cultural values and traditional natural resource management systems. They are generally large, with most of the area in a natural condition, where a proportion is under sustainable natural resource management and where low-level non-industrial use of natural resources compatible with nature conservation is seen.

\section{The guidelines and the issues}

The new guidelines were launched without apparent public dissent but there was a lot of dissent during the process of drafting. Analysis of what was said and written during this 
process suggests that, in some cases, attitudes are changing fast: things that would have been highly controversial a few years ago have now been widely accepted, whereas new issues that may cause debate in the future have only recently started to emerge.

\section{Issues that received little disagreement}

Three formerly controversial issues were accepted by virtually all the $>1,000$ IUCN member organizations with little further debate: the applicability of a wider range of governance types, assigning categories to zones within protected areas, and the role of small reserves.

Governance types The question of different governance models for protected areas has been the subject of intense debate (Redford \& Maclean Stearman, 1993; Noss, 1997). Although the IUCN definition of a protected area always encompassed the potential for different governance models, through inclusion of the phrase 'legal or other effective means' (IUCN, 1994), in practice almost all protected areas listed on the WDPA have been state owned and managed. In particular, full recognition of indigenous territories, community conserved areas and sacred natural sites as protected areas remained controversial, despite publication of IUCN guidance (Borrini-Feyerabend et al., 2004; Wild \& McLeod, 2008). In the event, the decision to incorporate different governance types within the IUCN framework received little or no comment in the meetings, electronic debates or written responses during the revision. The question seems to be moving away from whether or not they should be included, to under what conditions such areas should be recognized and managed as protected areas. This debate is ongoing but it seems likely that management approaches such as state forest reserves, various indigenous and community conserved areas (e.g. village forest reserves, wildlife management areas, community fisheries) and sacred natural sites will often but not always be equivalent to protected areas. Decisions will depend on analysis of the management aims and also on the desires of the managing body. For some community managed areas and sacred sites there may be good reasons for not wishing to be officially recognized and listed on the WDPA; for example, this could result in extra legal restrictions or attract visitors to sacred sites that are culturally private. A number of countries have made efforts to distinguish protected areas within some of these management approaches; for example, Uganda identified which forest reserves were also protected areas (Howard et al., 2003). Although some of these approaches will tend to fit into certain IUCN management categories (e.g. many sacred sites will be in Category Ia or III) there could be examples in any category. Questions about when private reserves have sufficient long-term security to qualify as protected areas differ between countries and general guidance still has to be developed.
Zoning A second long-running issue concerned zoning in protected areas and whether zones can be ascribed different categories (Agardy et al., 2003). This seemingly arcane issue is significant for countries with very large protected areas. It has been a particular source of contention in the case of the Great Barrier Marine Reef in Australia (Day, 2002), which until now has been listed as Category VI, a sustainable use reserve, but contains within it zones that represent one of the largest strictly protected marine areas in the world. The debates regarding category designation for zones seem to have more or less concluded before the current revision and proposals (Dudley, 2008); the proposal that zones could have their own categories only if they were legally and permanently designated (thus eliminating temporary management zones) passed without comment.

Small reserves There has long been frustration, especially in Europe, that many small reserves, such as protected pools or forest fragments, fell outside the IUCN system, not being strict reserves, wilderness, ecosystem or natural monuments and not receiving regular management intervention. In the past the practical role of such small reserves has been called into question (Woodroffe \& Ginsberg, 1998) and many have never been listed in the WDPA. In the 2008 guidelines the definition of Category IV (habitat/species management area) is changed from one based around process (protection that involves regular management intervention) to the objective of protecting particular species or habitat fragments. This implies that regular management will often be required because the site does not contain a fully functioning ecosystem but it is not an essential prerequisite (Dudley \& Borrini-Feyerabend, 2006). This issue was also dealt with in the new guidelines without controversy and allows thousands of protected areas to be added to the WDPA.

\section{Issues that were subject to intense discussion}

Continuing debates focused on more fundamental questions: what constitutes a protected area, whether all the management approaches included within the categories should be regarded as suitable for use in protected areas, whether management objective is the right basis for a typology and questions relating to the role of indigenous reserves.

The definition The first important question was about the definition of a protected area. The revised definition of a protected area gives greater weight to nature conservation, long-term security and management effectiveness. The 1994 IUCN protected area definition contained some ambiguity, probably because of differences in opinion during development of the 1994 guidelines. There was disagreement, even within IUCN, about whether 'maintenance of biological diversity' was always the, or at least a, 
primary objective of a protected area or whether it could be secondary to 'natural and associated cultural resources'. The 1994 guidelines stated that values other than conservation of biological diversity could be the primary objective in some categories: specifically that 'wilderness protection' was a primary objective of management in Category Ib and 'preservation of species and genetic diversity' a secondary objective; similarly that 'maintenance of traditional/cultural attributes' was a primary objective in Category V and 'preservation of species and genetic diversity' a secondary objective. However, these important points relating to priority of management were made in a single small matrix within the text; many users missed this and in practice assumed that biodiversity conservation was always a primary objective in protected areas. In effect, two interpretations operated in tandem with no resolution.

The debate hinges on whether protected areas should be confined to a relatively narrow spectrum of uses, all focused on biodiversity conservation, or whether instead they can represent a wider set of non-industrial interests that can include landscape values, local community needs and spiritual and cultural aspects. On the one hand, there are fears that protected areas will be diluted and their conservation values lost, on the other that overemphasis on narrow conservation aims will undermine other legitimate interests. Resolving this issue involved making a judgement based on what appeared to be a majority view, and a clear majority of IUCN members who took part in the debates favoured a new definition that moves the emphasis of management more closely towards conservation. Importantly, this is now accompanied by a set of principles, the most significant being 'For IUCN, only those areas where the main objective is conserving nature can be considered protected areas; this can include many areas with other goals as well, at the same level, but in the case of conflict, nature conservation will be the priority' (Dudley, 2008). This principle recognizes that many protected areas will have other values of equal importance, at least to some stakeholders (e.g. spiritual values), but that in the event of conflicting interpretations, nature conservation must take precedence. This is a clear way to distinguish a protected area recognized by IUCN from other management practices that are beneficial to conservation but where the management body is not prepared to give precedence to conservation. On the other hand, the focus of management in the definition has changed from 'biological diversity' to 'nature conservation', a broader term that embraces geodiversity and is more generally open to different cultural interpretations of what constitutes nature. Reaching a consensus within IUCN on this issue was the hardest part of the whole process.

Categories V and VI The second major debate related to whether Category V (protected landscapes/seascapes) and
Category VI (protected areas with sustainable use of natural resources) are really protected areas at all and, if so, how they should be managed. In an influential article Locke \& Dearden (2005) proposed that management in many of these areas paid so little attention to conservation that they should be removed from the WDPA. This would be highly significant as, for example, in Europe over half the area of protected areas is in Category V (Gambino, 2008). Locke \& Dearden (2005) drew responses arguing that landscape approaches are the most effective conservation mechanism in some situations (e.g. Mallarach et al., 2008) and initiated a debate about the value of Categories V and VI. The WCPA asked task forces on both categories to help to determine how the new guidelines would influence interpretation of these approaches.

There were also questions about the criteria for, and management of, these areas, particularly with respect to Category VI. In 1994 this was defined as an area that must be at least two-thirds completely natural (IUCN, 1994), with some kind of simple management (such as collection of non-timber forest products) in the remainder. However, practical application has never been as stringent as the guidelines suggested and during the review three very different proposals emerged: (1) keep the 1994 criteria of having two-thirds of the area completely natural; (2) remove or drastically reduce the requirement to have two-thirds of the area in a natural state while retaining the ban on industrial-scale activity (e.g. large-scale stock grazing or forestry); (3) open up the category dramatically to include sustainable large-scale logging and grazing (Dudley \& Stolton, 2008).

Many of the criticisms of Categories V and VI were addressed by the new definition, which in effect closes a loophole that previously allowed vague management designations to be listed as protected areas under these categories and ensures that all such areas should have clear conservation objectives. As a result all the categories were included in the guidelines without opposition and the importance of all the categories was the subject of a successful motion at the World Conservation Congress in Barcelona in October 2008.

Debates about the approach to conservation adopted in Category VI protected areas took more time to resolve. A meeting of conservationists in Latin America concluded that the 1994 controls were overly restrictive on an area that was supposed to combine conservation and sustainable use and this view was echoed by representatives from Small Island States in the Pacific. However, conservation organizations in Canada and Australia were afraid that eliminating the requirement would result in many spurious claims of protected area status for logging concessions and livestock ranches. The new guidelines are a compromise between these extremes, in effect allowing decisions regarding degree of naturalness to be taken at the national 
level. They state that Category VI is not suitable for areas where large-scale industrial activity takes place and suggest that national governments should determine if a proportion of the area needs to be in a natural condition for the category to apply and, if so, what this proportion should be.

Some other issues concerning these categories remain undecided. A more detailed set of guidelines on Category $\mathrm{VI}$ is planned, similar to that already available for protected landscapes (Phillips, 2002), which should help to resolve remaining questions about this approach. In addition, further research is needed on the role of IUCN Categories $\mathrm{V}$ and $\mathrm{VI}$ to determine under what conditions they are effective for biodiversity conservation and to develop case studies and guidance to help governments and others in establishing such approaches.

Management objectives Just as controversial was a proposal that the IUCN typology using management objectives be replaced by a system based on conservation outcomes (Boitani et al., 2008). The proposal suggested that the category system be changed in three ways: (1) Have the category designation tied to defined outcomes for the biodiversity elements for which the protected area is recognized or was designated: for example, a Category I protected area would be essential for the long-term viability of a targeted species, community or ecological system and would protect source populations and ecosystem occurrences. (2) Link categories to quantified goals for the biodiversity elements for which the protected area was designated: for example, Category I would require meeting requirements of strict size and naturalness to maintain populations or ecosystem processes; Category VI would make partial contributions to the maintenance of selected biodiversity. (3) Link protected area categories to the context of conservation planning frameworks and to the monitoring and evaluation of protected area management effectiveness.

Boitani et al. (2008) believed that a typology based on management objectives was fundamentally flawed and called for IUCN to abandon this in favour of one more closely linked to conservation outcomes. The WCPA countered that using a typology based on management objectives was a more practical method of categorization and had already been repeatedly endorsed by IUCN members. Rather than argue for management objectives vs biodiversity outcomes, there has been recognition that both may have their place as classification schemes and management tools. There are now at least four actual or potential typologies for defining protected areas: management objectives, governance types, biodiversity outcomes and management effectiveness. In theory other classification systems would be possible, for instance based around size or major biome. The WCPA and the IUCN Species Survival Commission are setting up a joint programme to look at options for categorizing protected areas by conservation outcomes.
Indigenous lands and waters Finally, there is general agreement that lands and water under the control of indigenous people can be regarded as protected areas if their management objectives meet the IUCN definition of a protected area. However, disagreement remains within indigenous peoples' movements about whether indigenous reserves should have their own separate category in the World Database on Protected Areas or, as at present, be potentially categorized under any of the management objectives (and listed as a separate governance type within the IUCN governance typology; Borrini-Feyerabend at al., 2004). Proponents believe that indigenous protected areas are unique in several respects and therefore require distinguishing from others. Opponents believe that adding a separate category is unnecessary and would present methodological difficulties by, in effect, providing a separate classification over that defined by management objectives, leading, in the case of its use in data management, to risks of double counting. At present there is a distinct category among governance types (indigenous peoples' protected areas and territories, established and run by indigenous people; Dudley, 2008) but not a separate management category. However, there is as yet no consensus among indigenous peoples' groups, either about classification or more generally about the potential relationship between official protected areas and official and unofficial indigenous territories.

This issue is still a long way from resolution. It will be important to build on the emerging consensus about the positive and potentially mutually beneficial role of indigenous and community conserved areas to work with stakeholders in identifying management frameworks and other practical steps, including long-term funding mechanisms.

\section{Conclusions}

The existence of the protected area estate is a testament to the social value placed on its existence by many countries and societies. As with many other social values there is a continuing evolution of the ways in which protected areas are conceived and managed. The robustness of the concept is evident in the changes over the last 40 years. Discussions over the definitions and categories of protected areas since 2004 reflect differences in the ways that stakeholders view the role of protected areas as a conservation tool. The long process of negotiation shows that the conservation community can reach agreement on protected area policy. The process needs to continue as new questions arise, for example about categorization of protected areas in the oceans. It is important not to lose momentum and to promote and build capacity around the new categories and continue building on progress to date. It is clear that as values change, so too will the interpretations of protected areas. It is vital to maintain resilience politically, socially 
and biologically if protected areas are to perform their vital functions in a rapidly changing world.

\section{References}

Agardy, T., Bridgenater, P., Crosby, M.A., Day, J., Dayton, P.K., Kenchington, R. et al. (2003) Dangerous targets: unresolved issues and ideological clashes around marine protected areas. Aquatic Conservation: Marine and Freshwater Systems, 13, 353-367.

Bishop, K., Dudley, N., Phillips, A. \& Stolton, S. (2004) Speaking a Common Language. IUCN, Gland, Switzerland, and University of Cardiff, Cardiff, UK.

Boitani, L., Cowling, R.M., Dublin, H.T., Mace, G.M., Parrish, J., Possingham, H.P. et al. (2008) Change the IUCN protected area categories to reflect biodiversity outcomes. PLoS Biology, 6, 436-438.

Borrini-Feyerabend, G., Kothari, A. \& Oviedo, G. (2004) Indigenous and Local Communities and Protected Areas: Towards Equity and Enhanced Conservation. Best Practice Protected Area Guidelines Series No. 11. IUCN, Gland, Switzerland, and Cambridge, UK.

Chape, S., Harrison, J., Spalding, M. \& Lysenko, I. (2005) Measuring the extent and effectiveness of protected areas as an indicator for meeting global biodiversity targets. Philosophical Transactions of the Royal Society B, 360, 443-455.

Colchester, M. (2003) Salvaging Nature: Indigenous Peoples, Protected Areas and Biodiversity Conservation. Forest Peoples Programme, Moreton-in-the-Marsh, UK.

DAY, J. (2002) Zoning: lessons from the Great Barrier Marine Park. Ocean and Coastal Management, 45, 139-156.

Dillon, B. (2004) The use of the categories in national and international legislation and policy. Parks, 14, 15-22.

Dudley, N. (ed.) (2008) Guidelines for Applying Protected Area Management Categories. IUCN, Gland, Switzerland.

Dudley, N. \& Borrini-Feyerabend, G. (2006) Review of the definition and selection of protected areas for species conservation. Species, 46, 26-28.

Dudley, N. \& Stolton, S. (eds) (2008) Defining Protected Areas: An International Conference in Almeria, Spain. IUCN, Gland, Switzerland.

ECOSOC (ECONOMic ANd Social Council of THE United NATions) (1961) United Nations List of National Parks and Equivalent Reserves. Economic and Social Council of the United Nations, New York, USA.

Gambino, R. (ed.) (2008) Parchi d'Europa. Verso una politica europea per le aree protette. ETS Edizioni, Pisa, Italy.

Howard, P., Davenport, T. \& Kigenyi, F. (2003) Planning conservation areas in Uganda's National Forests. Oryx, 31, 253-264.

IUCN (1994) Guidelines for Protected Area Management Categories. IUCN, Gland, Switzerland, and Cambridge, UK.
Koziell, I. \& Omosa, E. (2003) Room to Manoeuvre? Mining, Biodiversity and Protected Areas. International Institute for Environment and Development, and World Business Council on Sustainable Development, London, UK.

LOCKe, H. \& DeARDEN, P. (2005) Rethinking protected area categories and the new paradigm. Environmental Conservation, 32, 1-10.

Mallarach, J.M., Morrison, J., Kothari, A., Sarmiento, F., Atauri, J.A. \& Wishitemi, B. (2008) In defence of protected landscapes: a reply to some criticisms of category $\mathrm{V}$ protected areas and suggestions for improvement. In Defining Protected Areas: An International Conference in Almeria, Spain (eds N. Dudley \& S. Stolton), pp. 31-37. IUCN, Gland, Switzerland.

Noss, A.J. (1997) Challenges to nature conservation with community development in central African forests. Oryx, 31, 180-188.

Phillips, A. (2002) Management Guidelines for IUCN Category V Protected Areas: Protected Landscapes/Seascapes. Best Practice Protected Area Guidelines Series No. 9. IUCN, Gland, Switzerland, and Cambridge, UK.

Phillips, A. (2004) The history of the international system of Protected Area Management Categories. Parks, 14, 4-14.

Ravenel, R.M. \& REDFORD, K.H. (2005) Understanding IUCN protected area management categories. Natural Areas Journal, 25, 381-389.

Redford, K.H. \& Maclean Stearman, A. (1993) Forest dwelling native Amazonians and the conservation of biodiversity: interests in common or collision? Conservation Biology, 7, 248-255.

UNEP-WCMC (2008) State of the World's Protected Areas: An Annual Review of Global Conservation Progress. UNEP World Conservation Monitoring Centre, Cambridge, UK.

Wild, R. \& McLeod, C. (2008) Sacred Natural Sites: Guidelines for Protected Area Managers. Protected Area Technical Guidelines No. 16. IUCN, Gland, Switzerland.

Woodroffe, R. \& GinsberG, J.R. (1998) Edge effects and extinction of populations inside protected areas. Science, 280, 2126-2128.

\section{Biographical sketches}

Nigel Dudee is an environmental consultant focusing primarily on issues relating to protected areas and broad scale approaches to conservation, particularly in forest ecosystems. He chaired the World Commission on Protected Areas task force that revised the IUCN protected area management categories. JEFFrey D. PARRISH's interests are focused on migratory wildlife conservation and landscape scale conservation strategies. KENT H. REDFORD's work covers issues ranging from species conservation to protected area management across the 60 countries where the Wildlife Conservation Society works. Sue STOLTON is an environmental consultant with a special interest in protected areas, particularly with respect to international conventions, assessment of management effectiveness and planning, and issues related to understanding the wider values and benefits that protected areas can provide. 